
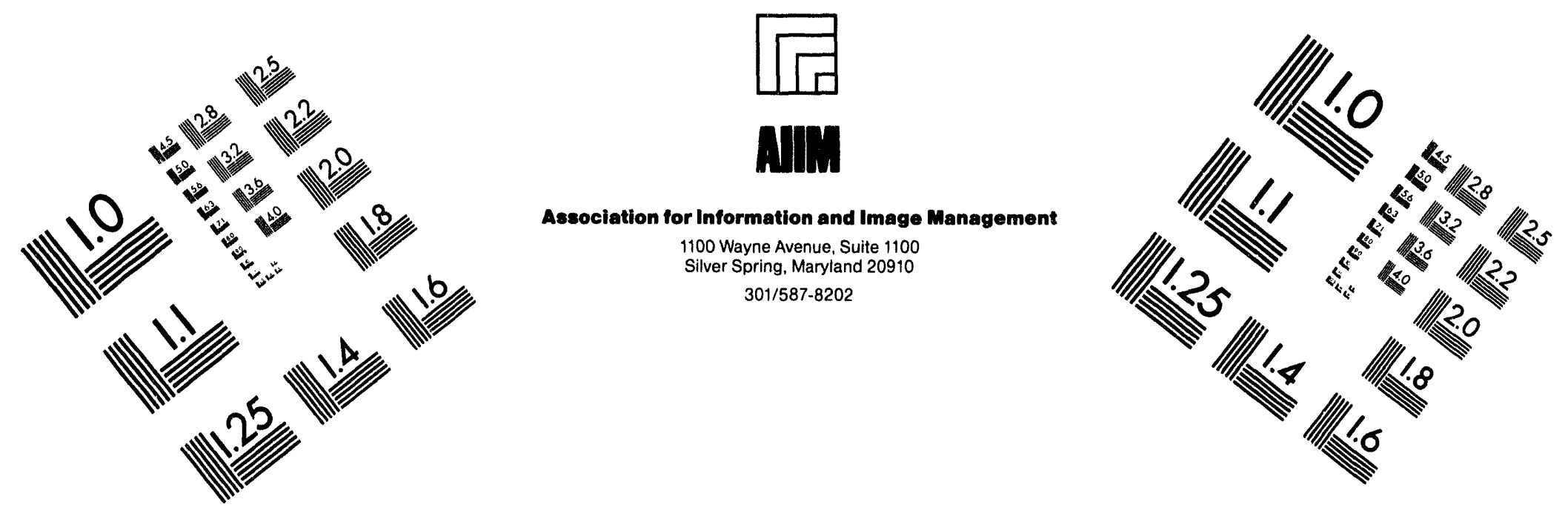

\title{
Centimeter
}

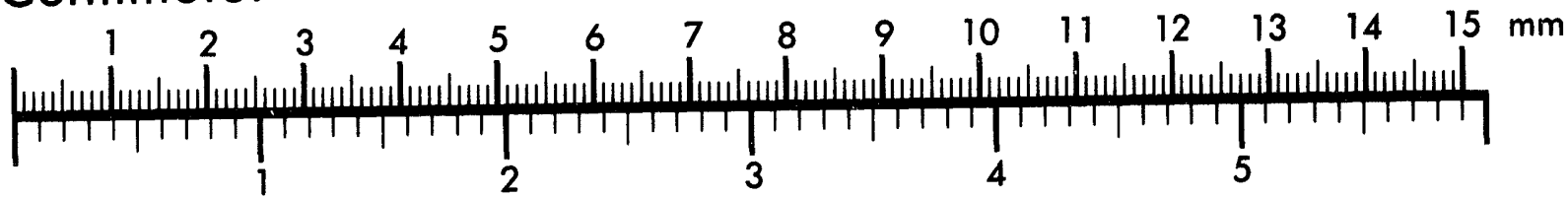

Inches
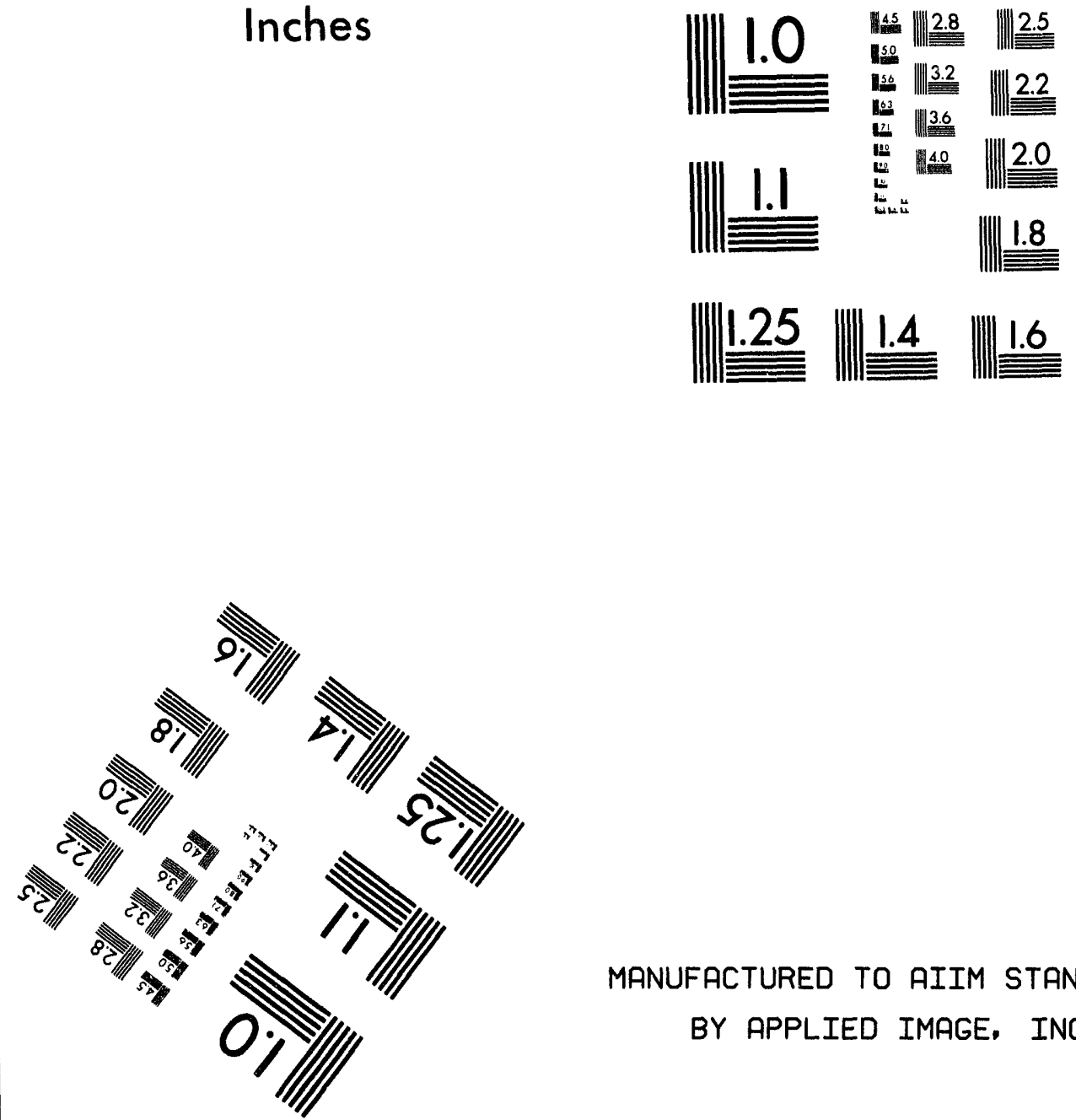

MANUFACTURED TO AIIM STANDARDS

BY APPLIED IMAGE, INC.

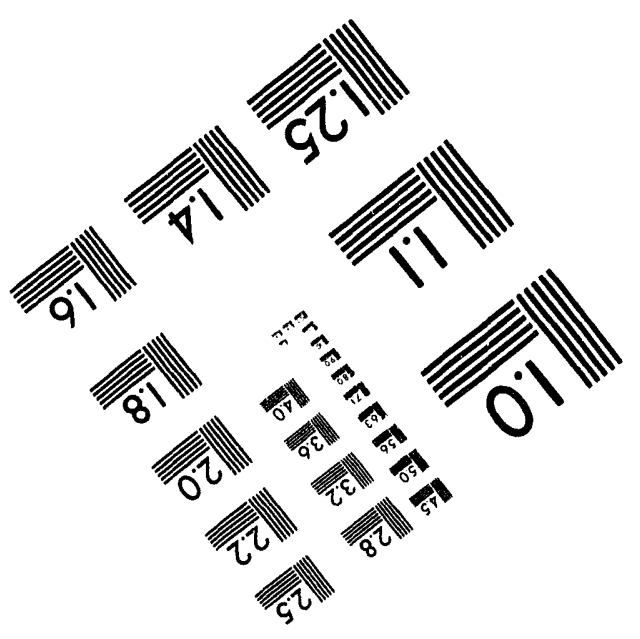



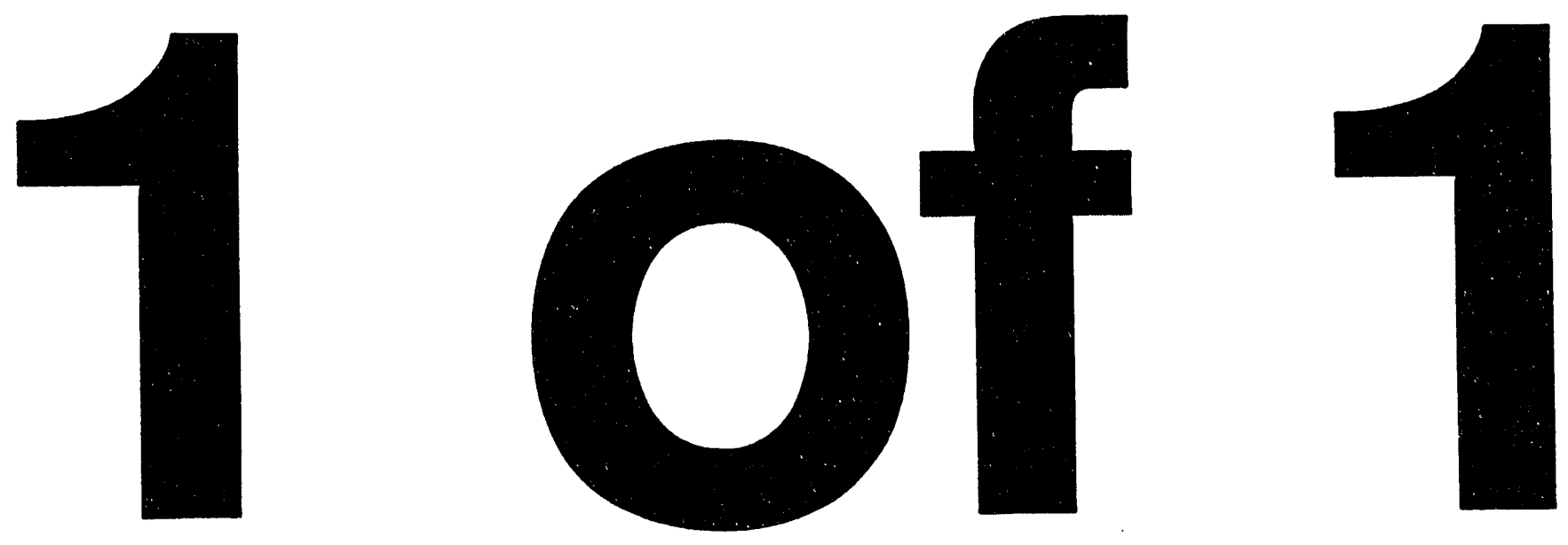

STORMS USING DRRCT AND ADJONTT METHODS

\author{
Seon Ki Park and Kelvin K. Droegemeier \\ Center for Analysis and Prediction of Storms and School of Metcorology, University of Oklahoma \\ Norman, Oklahoma 73019
}

\author{
and \\ Christian Bischof and Tim Knauff \\ Mathematics and Computer Science Division, Argonne National Laboratory \\ Argome, IL 60349
}

\section{BACKGROUND AND GOALS}

The goal of this project is to evaluate the sensitivity of numerically modeled convective storms to control peraneters such so the initial conditions, boundary conditions, environment, and various physical and computational parameters. In other words, we seek the gradient of the solution vector with respect to specified parameters. One cen use two approsches to eccomplish this tast. In the first or 20 called "brute force" method, one uses a fully nonlinear model to generate a control forecast starting from a specified initial stafe. Then, a number of other forecasts are made in which chosen parameters (e.8m initial conditions) are systematically varied (e.8. Droegemeier and Levit, 1993). The obvious drawback is that a large number of full model predictions are needed to exemine the effects of only a single parmeter.

A better approsch, thinking backward in time, is to specify a particular measure of the solution at the end of the forecast period, e.g. the surface pressure at a particular locetion at 2 hours, and then integrate backward in time to determine what parameters, say at the initial time, influence its value. This technique, which involves the adjoint of the forward model, has been used successfully to evaluate solution sensitivity (e.g., Errico and Vukicevic, 1992). Unfortunately, the formulation of an adjoint for even a modestly complex model is a tedious, highly time-intensive process that is prone to error and requires changes to the adjoint code every time the forwand model code is modified. In addition, the solution eensitivity 20 determined is limitod so linear variations about a specified forecast, and thus the adjoint method is unable to deal with regime transitions (e.g. between multicell and supercell storm types).

We describe herein an altemative, essentially automated method (ADIFOR, or Automatic Differentation of FORtran; Bischof et al. 1992) for obtaining the solution gradient that bypasses the adjoint altogether yet provides even more information about the gradient. (ADIFOR, like the adjoint technique, is constrained by the linearity assumption.) Applied to a 1-D moist cloud model, we assess the utility of ADIFOR relative to the brute force approsch and evaluate the validity of the tangent linear approximation in the context of deep convection.

\section{THE NUMERICAL MODEL.}

We use for our experiments a 1-D warm-rain Eulerian cloud model similar to that described by Ogura and Takahashi (1971, OT71 hereafter), using a forward-upstream numerical scheme. The model domain extends $10 \mathrm{lon}$ vertically with a
250 m grid spacing. The model prognoses vertical velocity $(w)$, temperabure (T), water vapor mixing ratio $\left(Q_{v}\right)$, cloud water mixing ratio $\left(Q_{C}\right)$ and rain water mixing ratio $\left(Q_{c}\right)$. The dynamical processes include advection, buoyangy, liquid water drag, interal eddy exchenge and dynemical entrainment, and the physical processes include condensation, evaporation of cloud and raindrops, and conversion from cloud to rain. The conversion rate of the latter, $C_{0}$, is set to 0.005 inverse seconds and will be the focal point of our sensitivity study.

The base state environment is dry adiabatic from the ground (25 C) up to $1 \mathrm{~km}$ and, thereafter, nearly moist adiabatic. The surface relative humidity of $94.5 \%$, increases at a rate of $5 \% / 250 \mathrm{~m}$ up $101 \mathrm{~km}$, and then decresses at the seme rate to the model top. Convection is initiated by imposing a parabolic updraft perturbation at low levels with a maximum of $1 \mathrm{~m} / \mathrm{s}$. Rigid lower and upper boundary conditions are used.

\section{RESULTS AND DISCUSSION}

\section{Control run and validity of the tangent linear model}

The control simulation made using the fully nonlines model (NLM) depicts the typical three-stage life cycle of a single-cell storm similar to that described by OT71. We developed from the nonlinear model code an aseocinted fintorder tengent lineas model (TLM) which predicts the evolution of perturbations about a state provided by the NLM. To teat the TLM, we conducted 12 experiments in which 5 to $60 \%$ errors were added to the initial updraft profile. For perturbations less than $15 \%$, the TLM correctly describes stom evolution up to $70 \mathrm{~min}$ as compared to its NLM counterpart likewise perturbed. However, for larger perturbations, the NLM storm intensifies absuptly between 15. $20 \mathrm{~min}$ and then oscillites, causing substantial disugreement with the TLM solution near cloud top where the strongest gradients of all variables exist. When even larger errors are introduced, the region of strong gradient near the cloud top moves upward during the mature stage in the NLM, causing even greater disagreement with the TLM.

\section{Results in the vicinity of regime change}

The conversion rate from cloud to rain, $\mathrm{C}_{\mathrm{o}}$, plays a major role in determining the life cycle of the modeled cloud (OT71). When $C_{0} \leq 4.096 \times 10^{-3}$, the cloud exhibits nerrly steady behavior, while for $C_{0} \geq 4.097 \times 10^{-3}$, the cloud is

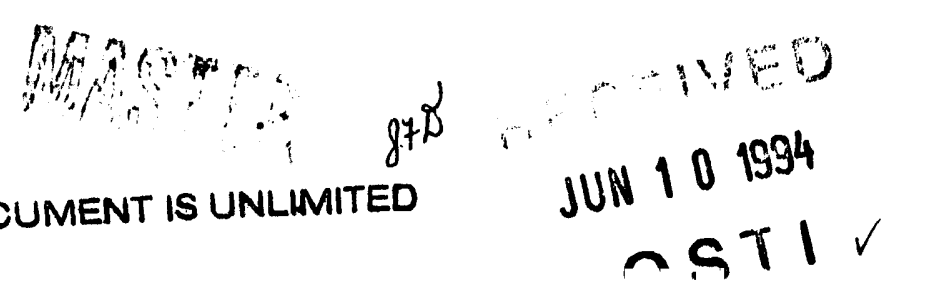


uncteady, with increasing $C_{0}$ reducins the lifetime of the cloud.

For reasonsbly emell chenges in $\mathbf{C}_{0}$ the $\mathbf{T} \mathbf{M}$ solution agrees well with that of the NLM, provided that one is not in the vicinity of a regime chenge. We have examined NLM experiments for three bave values of $\mathrm{C}_{0}$, onto each of which 10 pertubutions are added ranging from $10^{-7}$ w $10^{-4}$ (i.e. 30 expeximentr). For the stendy regime $\left(C_{0}=0.003\right)$, the NLC (nonlinearity cocticient, ien the rutio of the hipher-order nonlineer tems to the fint-onder lineer term) is well below mity throughort the simalation, indicating that the TLM is a sood approximation to the NLM eolutions. For the non-cteady regime $\left(C_{0}=0.005\right)$, the NLC abrupty rices above unity at abour $15 \mathrm{~min}$ for erros lerger then $4 \times 10^{-6}$ (Fig. 1a). For $C_{0}$ in the steady regime near the boundary of the regime chunge $\left(C_{0}=0.00409\right)$, the NLC shows a very shap incrense for errose larger then $7 \times 10^{-6}$ (Fig. 1b). The larger error beads to in earlier cocurrence of the sharp increase. We also obeerve thet the NLC is larger then unity for very small perturbations at early times for all cesee. This is dus to mechine round-off errer introduced by perturbations having a small magnituda. It is evident thet there exist a specific range of perturbations for which the TLM is valid. This experiment implies that we need to exercise caution in using gradient information from the TLM/ADM (edjoint model) system in the optimization process of data essimilation, especially when atmospheric conditions are in the vicinity of a regime change.

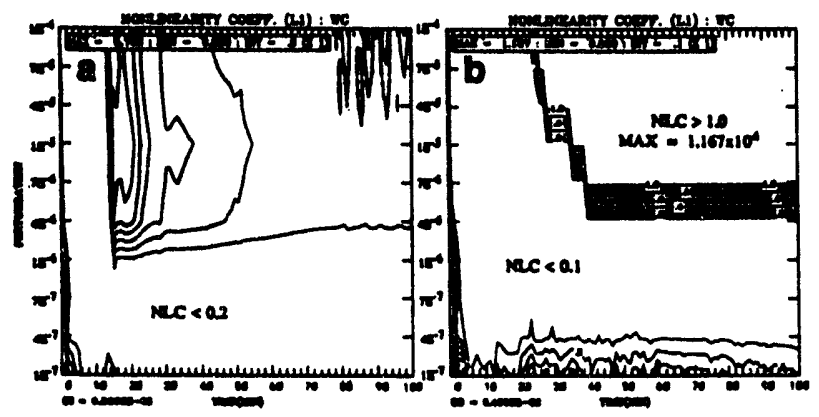

Fis. I Nonlinearity coefficients of $w$ field for 10 perturbation runs for a) $C_{0}=0.00409$ and b) $C_{0}=0.005$.

\section{Sensitivity of the model states to the control paraneters}

We explore the effects of three control parameters on cloud behavior: the cloud to rain conversion rate, $C_{0}$, a nondimensional proportionality constant, $\alpha_{,}$in the lateral eddy exchenge and the redius of the cloud, $R$. Values of these parameters in the control run are $0.005 \mathrm{~s}^{-1}, 0.2$ and $3 \mathrm{~km}$. respectively. Table 1 compares the forward sensitivity coefficient (FSC) and the relative sensitivity coefficient (RSC) at $\mathrm{t}=60 \mathrm{~min}$ for the total liquid water content, surface rainfall intensity and eccumulated precipitation. Here, FSC is defined as the change in a dependent variable at any intermediate time with respect to a unit change in an independent variable at the initial time, while RSC represents the percentage change of the former for $\mathbf{a} 1 \%$ chenge in the latter.

For a unit increase in each of the three parameters, all dependent variables show the least sensitivity with respect to
Table 1. Forward w. relative sensitivities at $t=60 \mathrm{~min}$ for verious dependent wariables

\begin{tabular}{|c|c|c|c|c|}
\hline \multirow[b]{2}{*}{ Sandivity } & \multirow{2}{*}{ 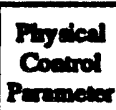 } & \multicolumn{3}{|c|}{ Depeadeat Veriables } \\
\hline & & $\begin{array}{l}\text { Toul Liquid } \\
\text { Waber Coment }\end{array}$ & $\begin{array}{l}\text { Ruhafill Imeandy } \\
\text { at Gound }\end{array}$ & Accomininen \\
\hline FSC & $\begin{array}{l}C_{0} \\
\mathbf{a} \\
\mathbf{R}\end{array}$ & $\begin{array}{l}\cos 13 \\
-25.106 \\
0.0016\end{array}$ & $\begin{array}{l}4145.9 \\
-62007 \\
0.0004\end{array}$ & $\begin{array}{r}1439.5 \\
-1.8474 \\
00001\end{array}$ \\
\hline Rsc & $\begin{array}{l}C_{0} \\
a \\
R\end{array}$ & $\begin{array}{l}00658 \\
-00004 \\
00004\end{array}$ & $\begin{array}{l}23290 \\
-0.1400 \\
\text { a.1408 }\end{array}$ & $\begin{array}{l}1.0030 \\
-00086 \\
00036\end{array}$ \\
\hline
\end{tabular}

R. However, the percentage chenge of the botal liquid water content for $a 1 \%$ chenge in $R$ is lerger then thit for $a 1 \%$ chenge in $\mathbf{C}_{\mathbf{o}}$. Furthermore, the percentage change in each dependent variable showe an identical rate of change for $\alpha$ and $R_{0}$ though in the oppovite direction. Both a and $\mathbf{R}$ apper in the lateral eddy exchange term, which is proportional to $\alpha / R$. Therefore, this behavior found was to be expected.

The FSC and local rensitivity coefirieient (LSC, defined as any sensitivity normalized by the domain maximum sensitivity) of $Q_{r}$ for a unit change in $C_{0}$ is presented in Fis. 2. The zero contour in the docaying atage matches the axis of

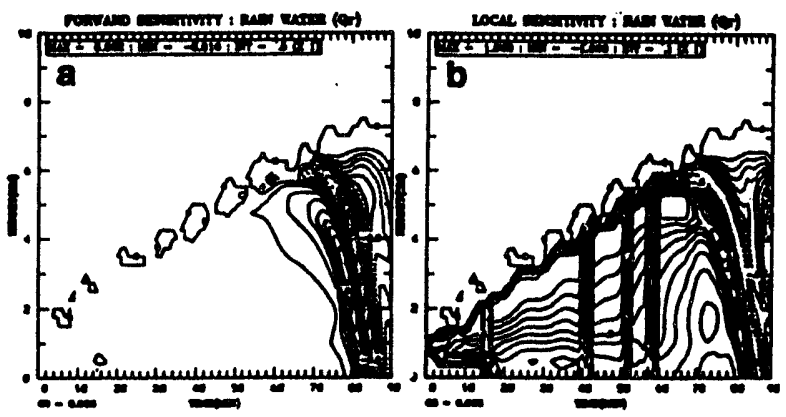

Fig. 2 a) Forward sensitivity vs. b) bocal sensitivity of $Q$, with respect $10 C_{0}$ for $C_{0}=0.005$.

the maximum rainwater $\left(\mathrm{AMQ}_{\mathrm{T}}\right)$ in control rum very well, where strong gradients are observed. The FSC show that an increase in $\mathrm{C}_{0}$ will result in an earlier onset and terminution of rainfall, which is physically plausible. However, little information is available locally for FSCs at earlier time due to their small magnitude. From the LSC analysis, we cm examine the local importance of the sensitivity at any simulation time in a relative sense. In Fig. 2b, we see three distinct stages in the behavior of sensitivity, which are relnted to the stages in the cloud's life cycle. During the developing tage (up to $15 \mathrm{~min}$ ). large sensitivities are obeerved a low levels with strong gradients both at the cloud top and bottom. which are mainly related to the local maxima of $\mathrm{Q}_{\mathrm{r}}$ obeerved at those regions in control run. In the mature stage, the largest sensitivities are observed at the cloud cop or in the layer just below it with strong gradient at the cloud top only. During the decaying stage, local maxima of sensitivities appear at lower layers and the strongest gradient is observed in all layers

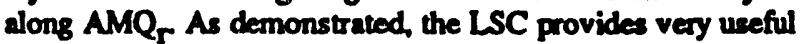
information on the local characteristics of the sensitivities. 


\section{Realle from the ADIFOR rm}

The ADTPOR-senerated code provides FSC of all dependent veribbles with reppect of all independent variables

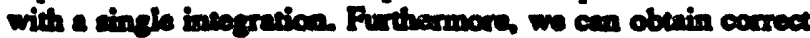
adjoint rensitivity cosficients (ASC) by computing $\partial X(t) \partial X(4-1)$ from reinitinlised ADTFOR rom, and then

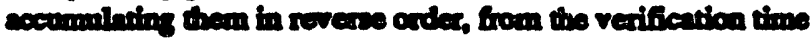
to the time of inereat The boll number of the dependent veristles is 204 and the of independent veriables is 661. Fip. 3 thowe PSCe and ASC computed from the ADIRORrenorated cods for a varification time of $t=90 \mathrm{~min}$. The inbels an each axin show the beight where the variables of intereat are boested.

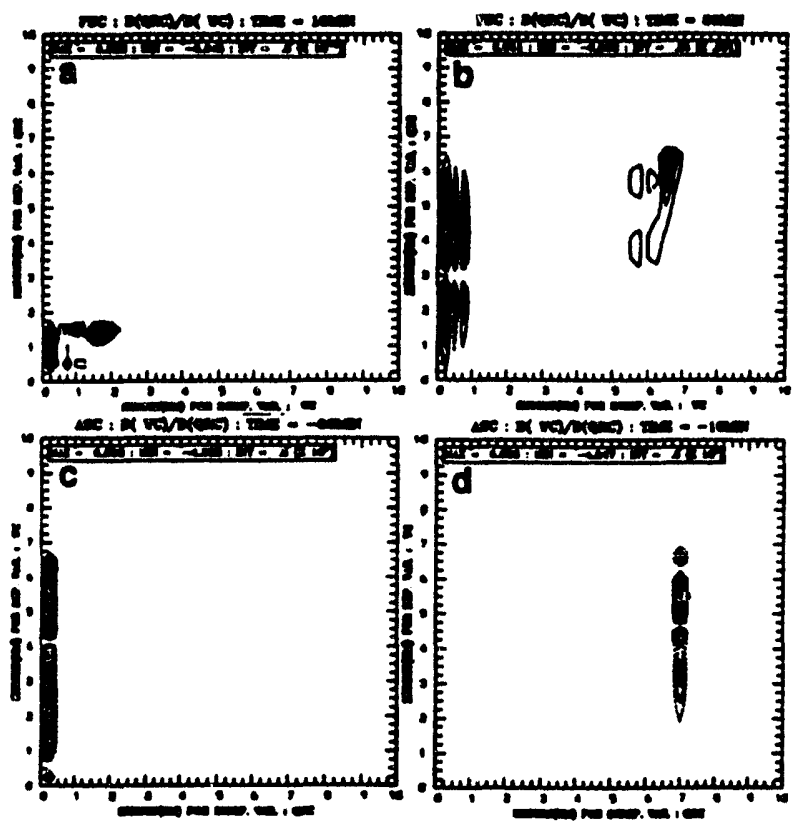

Fig. 3 Resubs from ADIFOR run. Fonword sensiviving of $Q$, with reqpect to $w$ for a) $8=10 \mathrm{~min}$ and $b$ ) $\mathrm{l}=80 \mathrm{~min}$ (upper pancl) and adjoint sensisivisy of $w$ with respect $10 Q$ or for $c)$ $t=-80 \min$ and $d) t=-10 \min ($ lowe panel).

For FSCa, we discus the censitivity of $Q_{\text {\& }}$ a any model time with respect $10 \mathrm{w}$ at the initivl time. In the developing stage $(l=10 \mathrm{~min})$, the change in $Q_{r}$ is bounded at lower levels below $2 \mathrm{~km}$ and is mostly affected by changes in the initial statc of $w$ located in the same region. Note that the initial wind maximum is located at $1 \mathrm{~km}$. The increase in $w$ below that level induces the increase in $\mathbf{Q}_{\mathbf{r}}$ inside the cloud lyyer. while an increase of the former above that level induces the increase of the latier only at the upper layer of the cloud. Throughout the mature stage, the largeat sensitivity of $Q_{\mathbf{r}}$ is obeerved at the cloud top for error inserted at that height in $w$ at the initial time (not shown). The latter tendency continues at early decaying stage $(t=80 \mathrm{~min})$. However, the area of sensitivity extends downward, which is apparently related to the downward tilt of $\mathbf{A M Q}$. Noteworthy censitivities are obcerved through all the cloud layer due to the change in the initial wind at levels below $1 \mathrm{~km}$.
The bover panel of Fig. 3 represenes AsCs which ewpinin the chenges in $w$ at verification time dos to the erose inseted in Q a any intermediste time. For chunges cocurred in Q. at the lowex level $(250 \mathrm{~m})$ during the developing ange $(t=-0$ $\mathrm{min}$ ), $w$ at verification time decreases in the $\mathrm{l} r \mathrm{rer} 14 \mathrm{~km}$ and increases bove that loyer. $w$ is not rencitive to chnoges in $Q_{\text {. }}$ cother level. This implies thet in operntional metecosoloy. we need good observations a retrievel of moisture a bow levels in the developing atege to prodict well the rubsegrese storm behnvior. In the matare atage $w$ in all colvmons of the clood is bighly sensitive to changes in Q $45-7 \mathrm{~lm}$ and relatively less sensitive to changes at lower levels (not shown). The lergent renvitivity in obwerved above the elond top, which implies thet mis-fining of $Q_{4}$ above the clond wp in the model may lead to a poor prediction of the bection of the cloud top during the decaying stage. In the docaying wangs

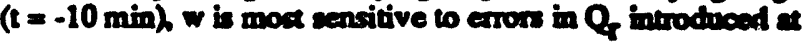
the cloud top. Those errors result in a decreane in w a 245 lan and incresse over the region where the cloud up is obeerved at verificetion time. Overill, the increase in Q, on or above the clood top results in an increase in the heipht of cloud top at the verification time which means bager duntion of the cloud system.

This kind of global analysis of sensitivities of model stutes to their eartier stages is almost impossible with the traditional TLM/ADM system. For large numbers of independent variables, the parallel proceasing can profitably be employed to decrease turnaround time. For an increase in parallel processors from 1 to 60 , the averaging execution times showed a hyperbolic decrense. Our ultimate sonl is to aply ADIFOR to the full 3-D ARPS model being doveloped by CAPS.

\section{ACKNOWLEDGMENTS}

This research was apported by NSF grant ATM92-22576 to the second anthor, and by grane ATM88-09862 to the Center for Analysis and Prodiction of Storms. Additional ruppont was provided to Argonne National Laboratory from the Ofirice of Scientific Computing. U.S. Department of Enery undex Contract W-31-109-Eng-38, and by the National Aexopece Agency under Purchase Order L25935D. We are gruteful for Sue Weygand of CAPS for her assintence with grophice and paste-up, and to Alm Carle of Rice University foc bis csential role in the ADIFOR project.

\section{REFERENCES}

Bischof, C. A. Carle, G. Corliss, A. Griewank, and P. Hovlend, 1992: ADIFOR - Cenerating derivative codes from Fortum progrems. Scientific Programming, 1, 11. 29.

Droegemeier, K. K, and J. J. Levit, 1993: The sensitivity of mumerically-simulated storm evolution to initial conditions. Preprints, 17th Conf. on Severe Local Starms, St. Louis, Missouri, Amer. Meleor. Soc. 431-435.

Errico, R. M. and T. Vukicevia, 1992: Sensitivity malysis using en adjoint of the PSU-NCAR mesoscale modal. Mon. Wea. Rev, 120, 1644-1660.

Ogura, $Y_{-}$and T. Takahashi, 1971: Numerical simulation of the life cycle of a thunderstorm cell. Mon. Wea. Rev, S. 895-sil.
The submitted manuscript has been authored by contractor of the U.S. Government under contrect No. W.31.109ENG-38. Accordingly, the U.S. Government retains a nonexclusive, royalty-tree license to publish or reproduce the publithed form of this contribution, or allow others to do 10 , for U. S. Government purposes. 

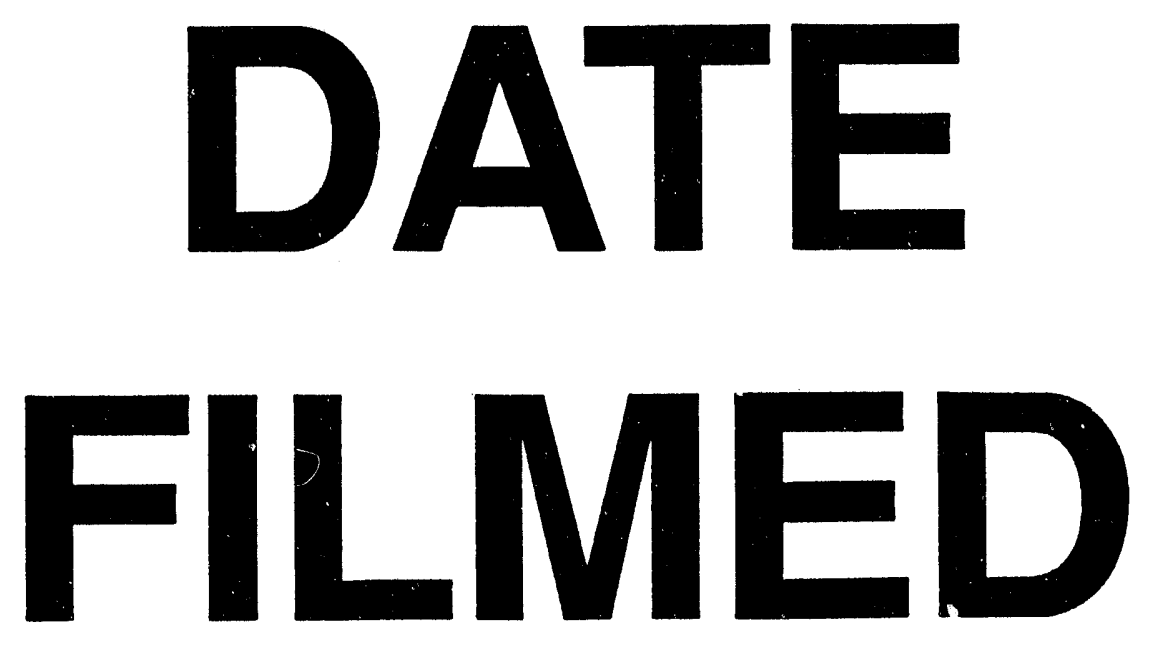

$8 / 11 / 94$
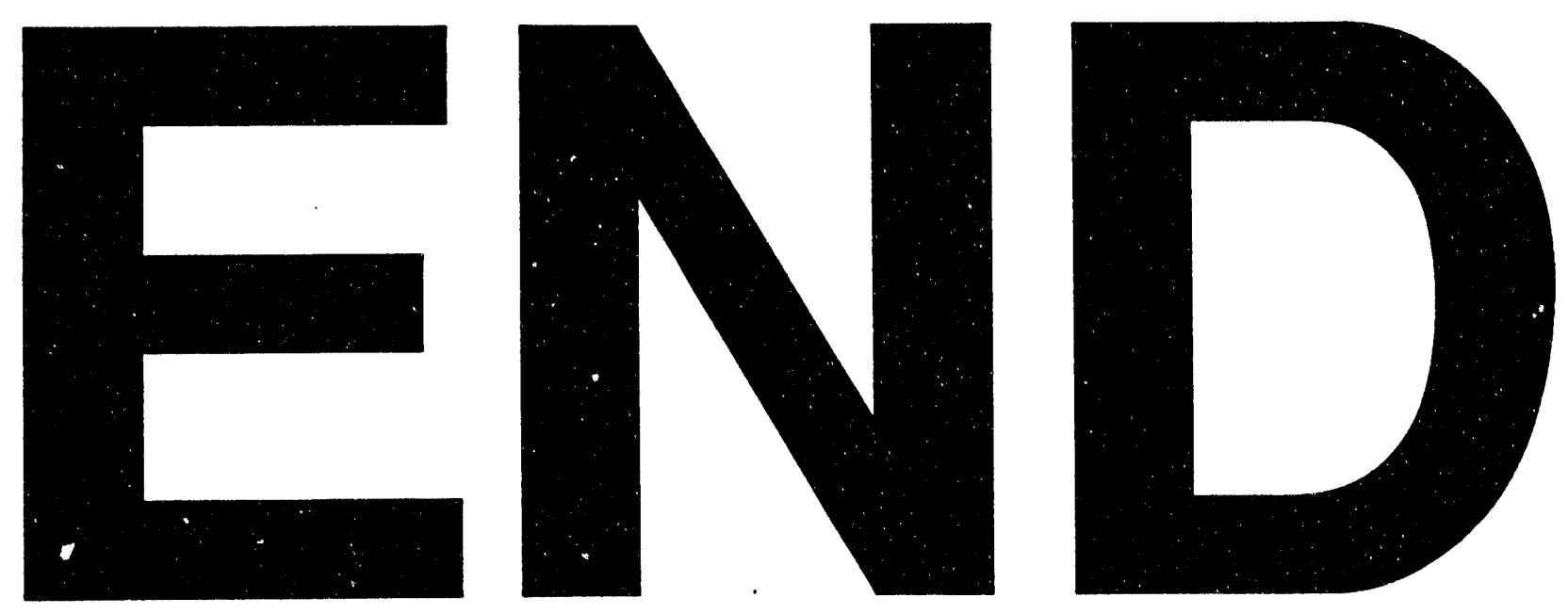


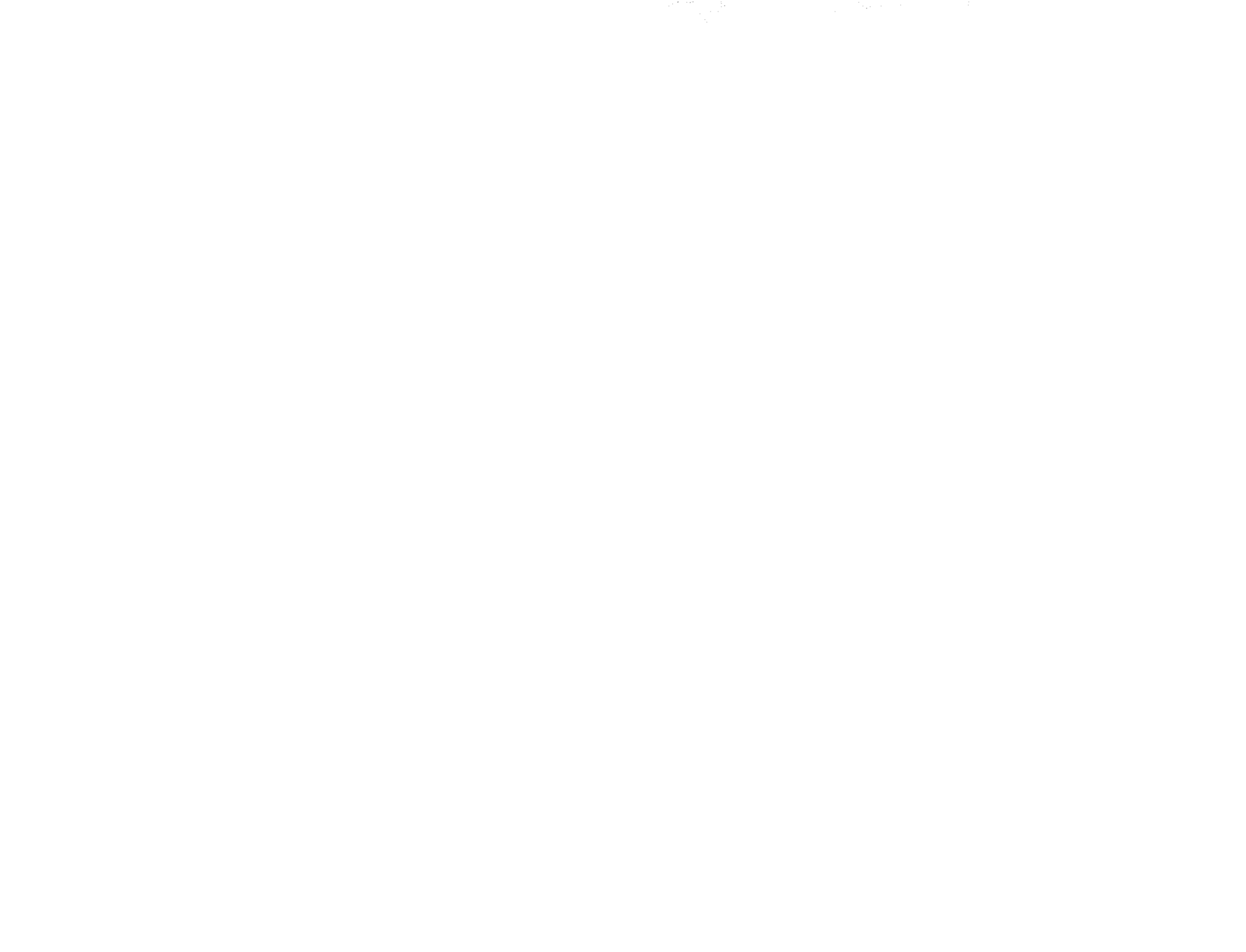

